Jpn. J. Genet. (1986) 61, pp. 253-269

\title{
Genetic differenciation in Japanese populations of Drosophila simulans and D. melanogaster. I. Allozyme polymorphisms
}

\author{
By Masayoshi Watada, Yoshiko N. ToBarI and Shigeru OHBA \\ Department of Biology, Faculty of Science, Tokyo Metropolitan University \\ 2-1-1 Fukasawa, Setagaya-ku, Tokyo 158
}

(Received June 1, 1986)

\begin{abstract}
Enzyme polymorphisms at 10 loci were studied both for $D$. simulans from the Japanese main island populations and Ogasawara population (the former has recently colonized and the latter has long been established) and for $D$. melanogaster from the main island and southern island populations including Ogasawara and Ryukyu Islands (these have been established). The proportion of polymorphic loci of $D$. simulans $(32 \%)$ was lower than that of $D$. melanogaster $(68 \%)$. However, a remarkable similarity in the average heterozygosities was found between $D$. simulans $(\mathrm{H}=0.154)$ and $D$. melanogaster $(\mathrm{H}=0.156)$. Differences in allele frequencies between years were small in both species. Among the 16 main island populations of $D$. simulans from Sapporo to Kagoshima, geographical uniformity of allozyme polymorphisms was found, but allele frequencies in the Ogasawara population were quite distinct from those of the main island populations. On the other hand, apparent geographical differentiation was found in $D$. melanogaster even among the 14 main island populations, as well as between the main island and Ogasawara populations.
\end{abstract}

\section{INTRODUCTION}

Drosophila simulans and Drosophila melanogaster have co-extensive wide range of distribution over the world in association with human habitations (Dobzhansky 1965, Bock and Wheeler 1972). These two sibling species are, however, largely rare or absent from Southeast Asia and West Pacific region (Bock and Wheeler 1972). Although D. melanogaster has been found in some localities including Japanese islands, $D$. simulans was reported only from the Ogasawara (Bonin) Island (Komai 1937, Kikkawa and Peng 1937, Okada 1956). Recently, however, $D$. simulans has immigrated into the main islands of Japan (Hokkaido, Honshu, Shikoku and Kyushu) and has been spreading rapidly (Watanabe and Kawanishi 1976, 1978). Population genetic studies of newly colonizing species, such as $D$. simulans in the main islands of Japan, may provide important information about the founder effect, processes of genetic differentiation, and the factors affecting the establishment of the differentiation.

The objective of the present study was to investigate the allozyme poly- 
morphisms in newly colonizing populations of $D$. simulans in the main islands of Japan, comparing them with the long term established sympatric populations of $D$. melanogaster. The comparison demonstrated the geographical uniformity in the main island $D$. simulans populations, contrasting with considerable geographical divergence in $D$. melanogaster populations in the same region.

\section{MATERIALS AND METHODS}

Collection of fies

$D$. simulans and D. melanogaster were collected from various localities in the main islands of Japan, Ogasawara Islands, and Ryukyu Islands. Detailed information about the collections is summarized in Table 1 and Fig. 1. Flies around human habitations were collected using banana bait traps. In some

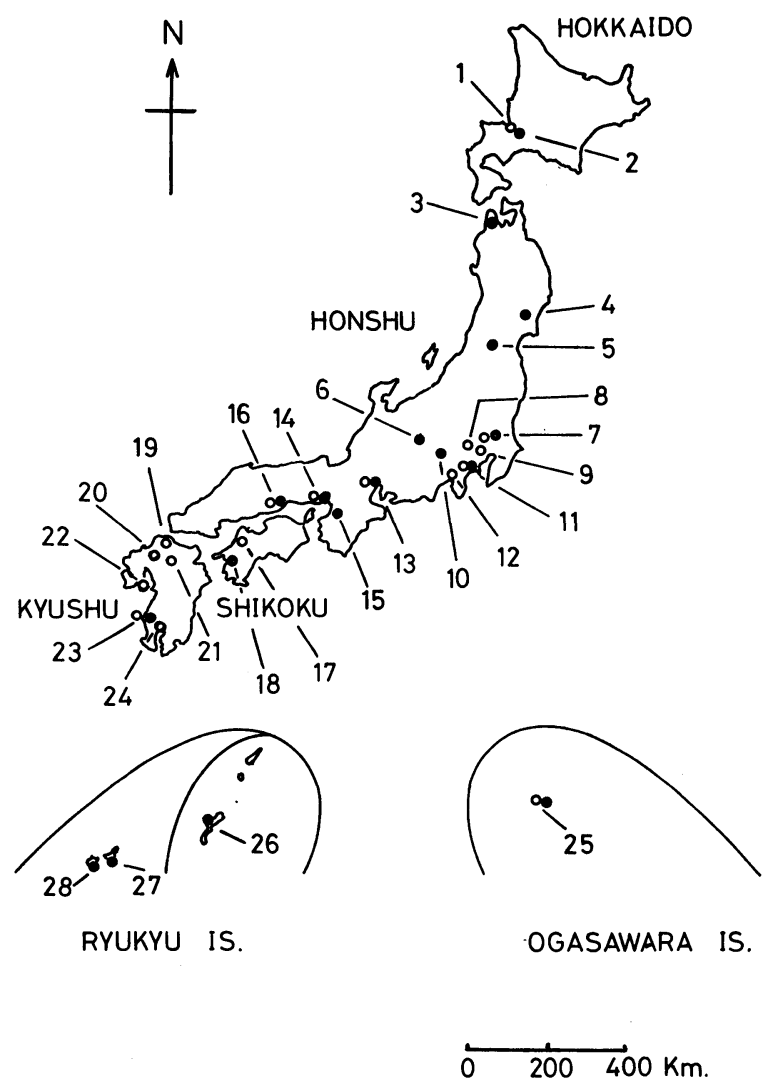

Fig. 1. Geographical distribution of sampling localities of Drosophila simulans (open circles) and D. melanogaster (darkened circles). Numbered localities correspond to those listed in Table 1. 
Table 1. Localities, collection dates and habitats of Japanese populations of Drosophila simulans and Drosophila melanogaster surveyed in the present study

\begin{tabular}{|c|c|c|c|c|c|}
\hline No. & Locality & (abbr.) & Species & $\begin{array}{c}\text { Date } \\
\text { (month/year) }\end{array}$ & Habitat \\
\hline 1 & Sapporo I & (SPPI) & simulans & Sept./77 & human habitation \\
\hline 2 & Sapporo II & (SPPII) & melanogaster & Sept./77 & beer brewery \\
\hline 3 & Tsugaru & (TGR) & melanogaster & Oct. $/ 78$ & vineyard \\
\hline 4 & Kogota & $(\mathrm{KGT})$ & melanogaster & Oct. $/ 78$ & human habitation \\
\hline 5 & Akayu & $(\mathrm{AKY})$ & melanogaster & Oct./77, Oct./78 & vineyard \\
\hline 6 & Shiojiri & (SOJ) & melanogaster & Oct. $/ 77$, Oct. $/ 78$ & vineyard \\
\hline 7 & Omiya & (OMY) & simulans, melanogaster & Sept./77, Nov./78 & human habitation \\
\hline 8 & Kokubunji & $(\mathrm{KKB})$ & simulans & Aug./77 & human habitation \\
\hline 9 & Setagaya & (STG) & simulans & Aug./77 & human habitation \\
\hline 10 & Katsunuma & $(\mathrm{KTN})$ & melanogaster & Aug./77, Oct./78 & vineyard \\
\hline 11 & Oiso & (OIS) & simulans, melanogaster & Sept./77, Nov./78 & human habitation \\
\hline 12 & Mishima & (MSM) & simulans & Nov. $/ 77$, Nov. 78 & human habitation \\
\hline 13 & Nagoya & (NGY) & simulans, melanogaster & Oct. $/ 78$ & human habitation \\
\hline 14 & Shukugawa & (SKG) & simulans, melanogaster & Oct./77, Sept./78 & human habitation \\
\hline 15 & Habikino & (HBK) & melanogaster & Aug./78 & vineyard \\
\hline 16 & Okayama & $(\mathrm{OKY})$ & simulans, melanogaster & Sept./78 & vineyard \\
\hline 17 & Matsuyama & (MTY) & simulans & Nov./77, Nov./78 & human habitation \\
\hline 18 & $\mathrm{Ozu}$ & (OZU) & melanogaster & Oct./77 & human habitation \\
\hline 19 & Kokura & $(\mathrm{KKR})$ & simulans & Nov./77, Sept./78 & human habitation \\
\hline 20 & Harazuru & (HRZ) & simulans & Nov./77 & persimmon yard \\
\hline 21 & Bungomori & (BNG) & simulans & Nov./77 & human habitation \\
\hline 22 & Shimabara & (SMB) & simulans & Nov./77 & human habitation \\
\hline 23 & Izumi & $(\mathrm{IZM})$ & simulans, melanogaster & Nov./77, Sept./78 & human habitation \\
\hline 24 & Kagoshima & (KGS) & simulans & Nov./77 & human habitation \\
\hline 25 & Ogasawara & (OGS) & simulans, melanogaster & Dec./77, July/78 & human habitation \\
\hline 26 & Okinawa & $(\mathrm{OKN})$ & melanogaster & Feb. $/ 78$ & pineapple yard \\
\hline 27 & Ishigaki & (ISG) & melanogaster & Feb./78 & pineapple yard \\
\hline 28 & Iriomote & (IRO) & melanogaster & Feb./78 & human habitation \\
\hline
\end{tabular}

other habitats (mostly vineyards, beer breweries, and pineapple yards), flies were collected by sweeping. Flies of both species were sampled from eight geographic populations in two successive years, 1977 and 1978. In most cases, collected flies were frozen at $-30^{\circ} \mathrm{C}$ for a few months, until electrophoresis.

\section{Electrophoresis}

Usually, wild caught females were used for electrophoresis. However, when the number of wild females was insufficient, wild caught males and $F_{1}$ females were also used. For both species, the following 10 enzymes (abbreviation in parentheses) were commonly assayed by horizontal thin layer gel 
electrophoresis: acid phosphatase (ACPH), alcohol dehydrogenase (ADH), $\alpha$ amylase (AMY), esterase-6 (EST-6), esterase-C (EST-C), glucose-6-phosphate dehydrogenase (G6PDH), $\alpha$-glycerophosphate dehydrogenase ( $\alpha$-GPDH), malate dehydrogenase (MDH), malic enzyme (ME), and octanol dehydrogenase (ODH). Procedures for electrophoresis were the same as described by Fukatami (1977), with minor modifications in the buffer systems used in detecting EST-6 and EST-C. Conditions for electrophoresis and enzyme assays were nearly the same as described by Aotsuka (1980) and Ayala et al. (1972). Allozymes representing alleles at each locus were designated alphabetically by increasing order of mobility. Genetic distances between populations and between species were calculated according to Nei's formula (1972) from the allozyme allele frequencies.

Estimation of effective population size

From Omiya populations, male flies of $D$. melanogaster were collected in July of 1979 in order to estimate the effective size of the population based on the allelism rate of lethal genes (Kosuda et al. 1969). The number of loci and mutation rate of lethal genes were used following those estimated by Mukai and Yamaguchi (1974).

\section{RESULTS}

Electrophoretic variants

Table 2 shows the number of alleles at 10 enzyme loci examined, specific to each species, common to both species, and the total at each locus. In $D$. simulans, only four loci out of ten (Est-C, Est-6, Acph, and Odh) showed

Table 2. Number of alleles at 10 enzyme loci in Drosophila simulans and Drosophila melanogaster

\begin{tabular}{lcccc}
\hline Enzyme & D. simulans & D. melanogaster & Shared alleles & Total \\
\hline ACPH & 3 & 2 & 0 & 5 \\
ADH & 1 & 2 & 0 & 3 \\
AMY & 1 & 6 & 1 & 6 \\
EST-6 & 3 & 4 & 3 & 4 \\
EST-C & 6 & 3 & 2 & 7 \\
G6PDH & 1 & 4 & 1 & 4 \\
$\alpha$-GPDH & 1 & 2 & 1 & 2 \\
MDH & 1 & 2 & 1 & 2 \\
ME & 1 & 2 & 1 & 2 \\
ODH & 4 & 4 & 4 & 4 \\
\hline Total & 22 & 31 & 14 & 39 \\
\hline
\end{tabular}


polymorphisms, whereas all ten loci of $D$. melanogaster were polymorphic. At two loci, $A d h$ and $A c p h$, no alleles common to both species were detected. The number of alleles per locus was larger in D. melanogaster (3.1) than in D. simulans (2.2). Twentyfive $(64 \%)$ out of 39 alleles in total were species specific, of which $17(68 \%)$ were found in $D$. melanogaster. These results showed striking similarity to those of these two species reported by Berger (1970) in American populations. In the present study, some rare variants were newly found at the following loci: Acph of D. simulans, G6pdh in $D$. melanogaster, and Odh in both species.

Enzyme polymorphism of D. simulans

In $D$. simulans, twentyfive samples from 17 localities including Ogasawara, were studied (Table 3). Three out of ten loci (Est-C, Est-6 and Acph), were found to be highly polymorphic throughout all samples. At the Odh locus, only Kyushu and Ogasawara populations were polymorphic. The average proportion of polymorphic loci was estimated to be $0.32 \pm 0.01$. Average heterozygosity was $0.154 \pm 0.002$ for all $D$. simulans populations, although that was lower in the Ogasawara population, 0.125 in 1977 and 0.138 in 1978.

Most of the main island populations were found to be similar in allele frequencies at three polymorphic loci, Est-C, Est-6 and Acph, with some exceptions found in the samples from Shukugawa and Kokura in 1977. On the other hand, the Ogasawara population (both in 1977 and 1978) were considerably different from the main island populations in the allele frequencies at the Est-C and Acph loci.

Rare alleles were observed at four loci, (Est-C, Est-6, Acph and Odh) in populations from both the main islands and Ogasawara. Among them the Est- $\sigma^{d}$ allele was found in 10 localities in the main islands, but not in the Ogasawara population. Other rare alleles, $A c p h^{d}, O d h^{b}$ and $O d h^{d}$, were also found only in some main island populations, but not in the Ogasawara population. In all eight populations surveyed, allele frequencies at each locus remained the same in two successive years with the exceptions of Est-C and Est- 6 in the Shukugawa population.

\section{Enzyme polymorphism in D. melanogaster}

The allele frequencies at the ten enzyme loci of $D$. melanogaster are shown for all samples in Table 4. Variants were found at all ten loci studied, although the degree of polymorphism varied among loci. The average proportion of polymorphic loci was $0.68 \pm 0.02$, significantly higher than that of $D$. simulans $(0.32 \pm 0.01)$. In the Ogasawara population, however, the proportion of polymorphic loci was 0.4 in 1977 and 0.5 in 1978, lower than those of other populations. The average heterozygosity in D. melanogaster was $0.156 \pm 0.006$, which was similar to that of $D$. simulans $(0.154 \pm 0.002)$. However, the range 
M. WAtAda, Y. N. Tobari and S. OHbA

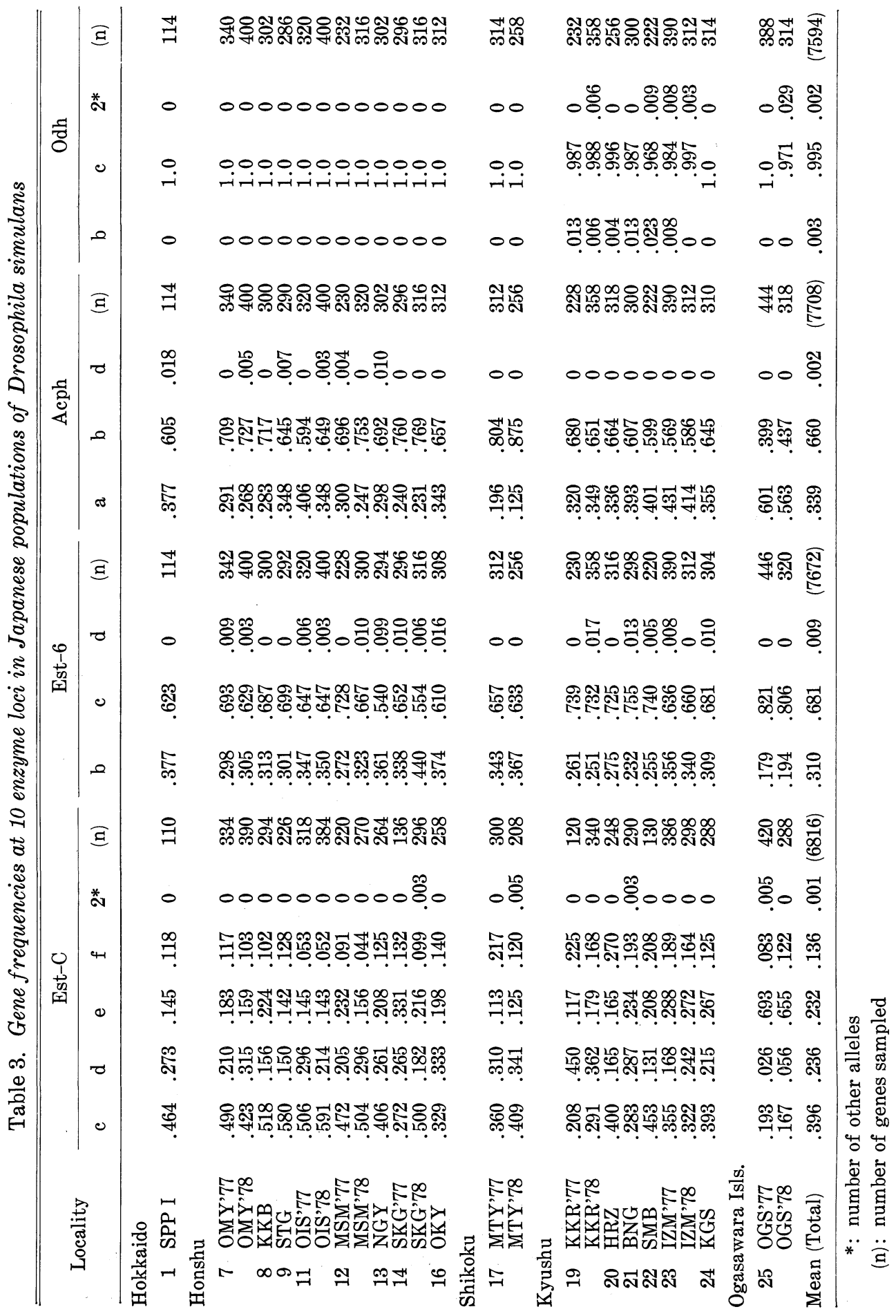




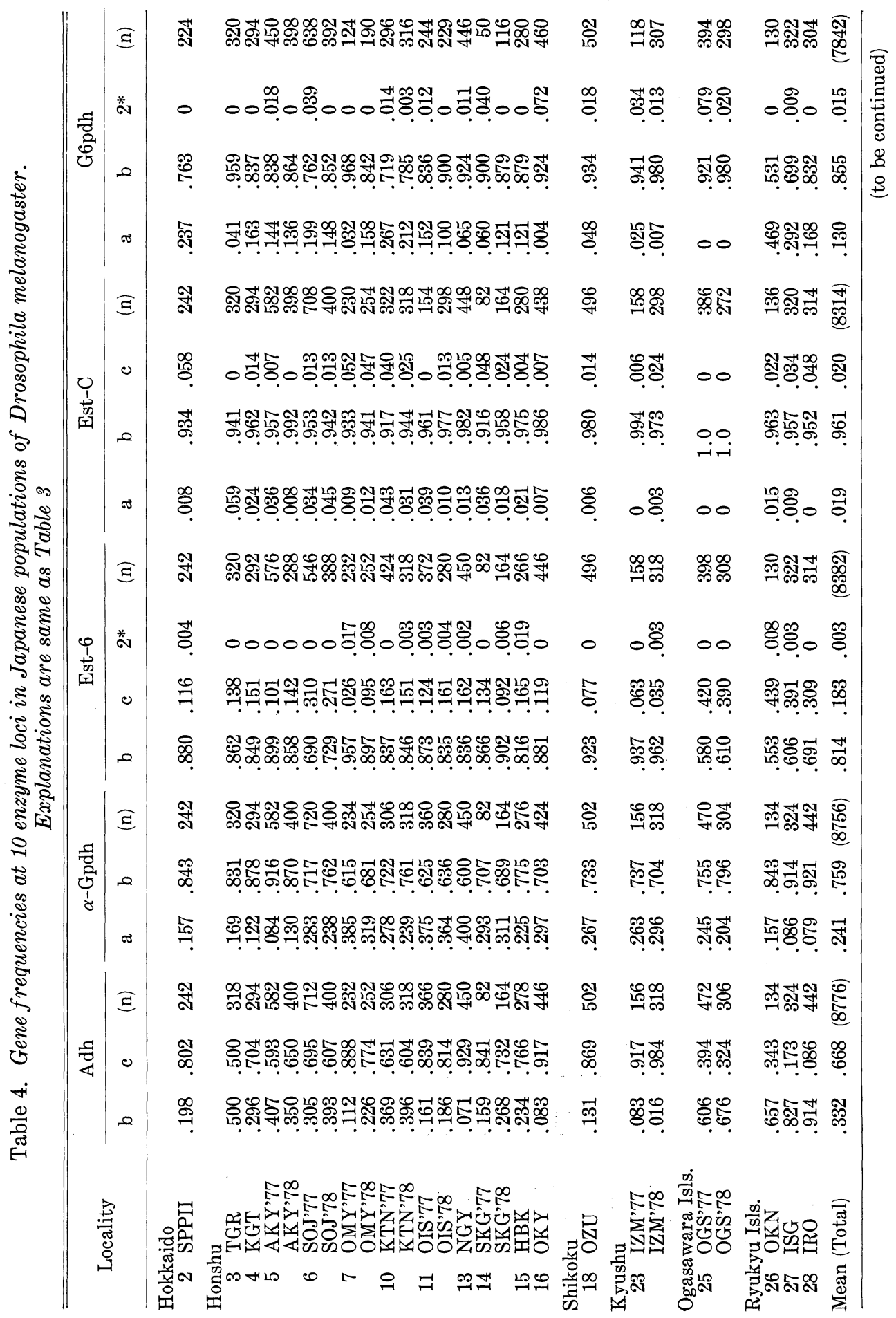




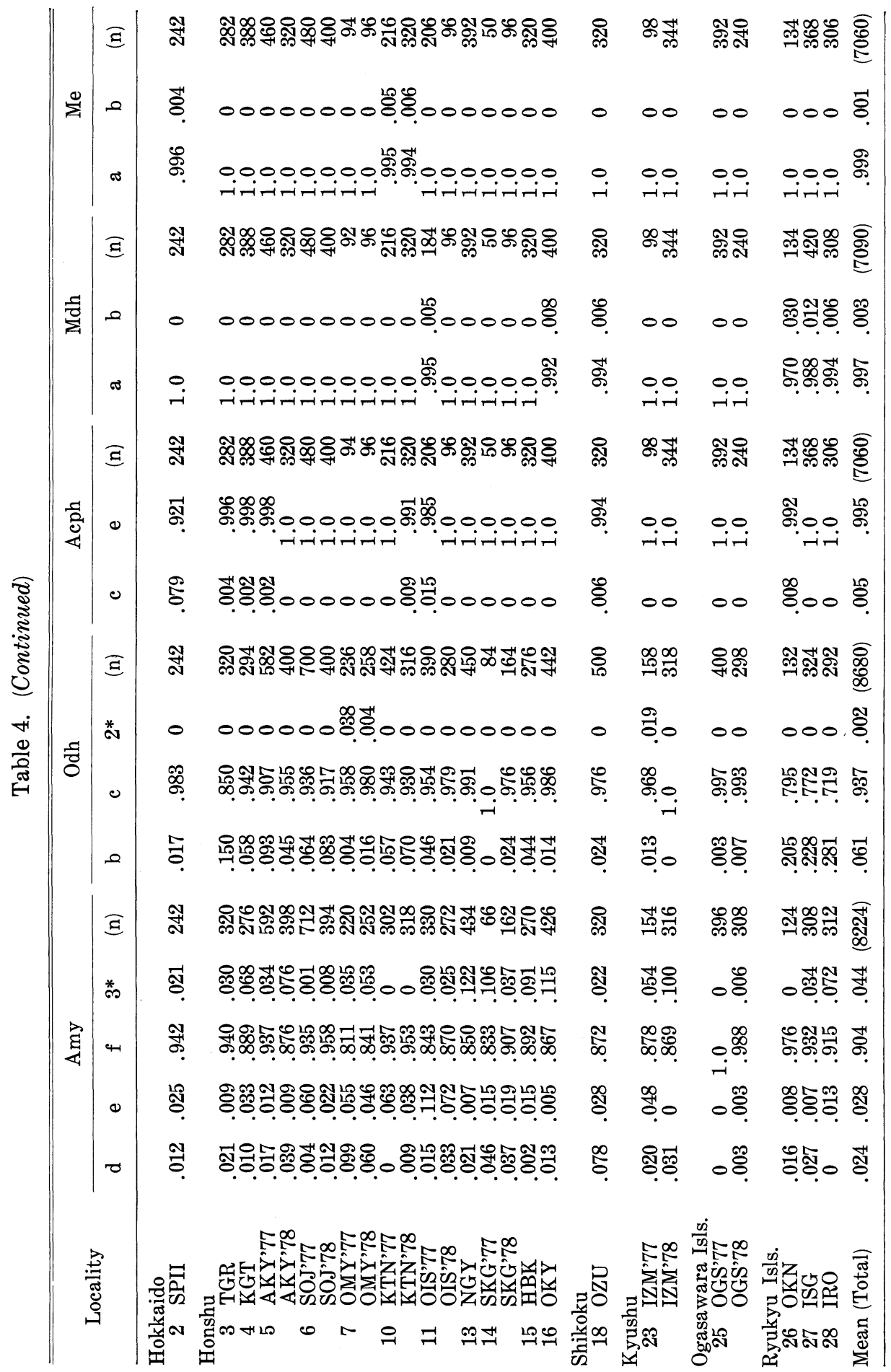


of average heterozygosities in the populations of $D$. melanogaster was wide (0.085-0.223). Low average heterozygosies were observed in Izumi $(0.107$ in 1977 and 0.085 in 1978), Okayama (0.125), and Ozu (0.123). On the other hand, the highest average heterozygosity was found in Okinawa island (0.223). The frequency of $A d h^{b}$ ( $A d h^{s}$ by previous workers) allele was found to be the most variable among populations, from 0.914 (Iriomote) to 0.016 (Izumi): higher allele frequencies were observed in Ogasawara and Ryukyu Islands (Okinawa, Ishigaki and Iriomote) and in the northern part of the main islands, especially in vineyard populations. At three loci, $\alpha-G p d h, E s t-6$ and $G 6 p d h$, the allele frequencies varied from population to population, although the range of variation was not so wide as that of $A d h$. The frequency of $\alpha-G p d h^{a}$ was higher in the central region of Honshu, especially in the populations near human habitation (Omiya, Oiso, and Nagoya). At both the Est- 6 and G6pdh loci, similar geographical distributions in allele frequencies were found: frequencies of Est- $6^{c}$ and $G b p d h^{a}$ were higher in the central part of Honshu (Shiojiri and Katsunuma) and southern islands (Ryukyu and Ogasawara). There were three loci, Est-C, Amy and $O d h$, in which one allele was in high frequency $(80-90 \%)$ in most populations studied and relatively less divergent among populations. The three loci, Acph, $M d h$ and $M e$, were found to be monomorphic in most populations, although rare variants were detected in some populations; e.g. $A c p h^{\circ}$ comprised more than $7 \%$ of the Sapporo population.

In eight populations of $D$. melanogaster including Ogasawara, allele frequencies at ten loci were similar for the two succesive years, 1977 and 1978, except for the Omiya population, in which frequencies of some alleles changed more than $10 \%$ between the two years at the $A d h$ and G6pdh loci.

\section{Effective population size of Omiya population in D. melanogaster}

Effective population size was estimated using 248 males collected from the Omiya population in July of 1979 , in order to determine whether random genetic drift might be a possible factor which caused the difference in allozyme frequencies between years descrived above. The percentage of each viability class, as adopted by Kosuda et al. (1969), was as follows: lethal, $20.6 \%$ (51/248); semi-lethal, 4.0\% (10/248); subvital, 12.5\% (31/248); normal, $62.5 \%$ (155/248); and super-vital, $0.4 \%$ (1/248). Allelism rate estimated by all possible combinations between 37 complete lethal genes was $2.1 \%$ (14/666). From the results, the effective population size of the Omiya population was estimated to be about 3,300 .

\section{Genetic differentiation in. D. simulans and D. melanogaster}

The mean genetic distances between years, between geographical popula- 
Table 5. The average genetic distance (Nei 1972) for various criteria, calculated from allele frequencies at 10 enzyme loci of Drosophila simulans and Drosophila melanogaster. Number in parentheses is combination number

\begin{tabular}{lccc}
\hline \multicolumn{1}{c}{ Criteria } & \multicolumn{2}{c}{ D. simulans } & D. melanogaster \\
\hline overall & $0.0091 \pm 0.0006(300)$ & $0.0244 \pm 0.0015(325)$ \\
between years & $0.0017 \pm 0.0006(8)$ & $0.0020 \pm 0.0004(8)$ \\
within mainlands & $0.0049 \pm 0.0002(253)$ & $0.0093 \pm 0.0005(210)$ \\
between mainlands and Ogasawara Isls. & $0.0327 \pm 0.0014(46)$ & $0.0354 \pm 0.0022(42)$ \\
between mainlands and Ryukyu Isls. & - & $0.0682 \pm 0.0034$ & $(63)$ \\
between species. & \multicolumn{3}{c}{$0.6967 \pm 0.0020(650)$} \\
\hline
\end{tabular}

tions, and between species of $D$. simulans and $D$. melanogaster are shown in Table 5. In both species, genetic distances were small between years (0.0017 in D. simulans and 0.0020 in D. melanogaster) as compared with the distances among the geographical populations. Genetic distances among the geographical populations of $D$. melanogaster were generally larger than those found in D. simulans. Among the main island populations, the distance of $D$. melanogaster (0.0093) was about twice as large as that of $D$. simulans (0.0049). The average distances between the main island populations and the Ogasawara population were 0.0327 in $D$. simulans and 0.0354 in D. melanogaster. The largest genetic distance was found between the main islands and Ryukyu populations of $D$. melanogaster $(0.0682)$. It is clear that, especially in D. simulans, the genetic distance within the main island populations were smaller than those between the main island and Ogasawara populations. The genetic distance between the two sibling species was $0.697 \pm 0.002$, which was considerably larger than those among populations within each species $(0.0017-$ 0.0682 ).

\section{DISCUSSION}

The present study showed that the proportion of polymorphic loci $(0.68)$ in $D$. melogaster was larger than that $(0.32)$ in $D$. simulans. In contrast, the average heterozygosity of $D$. melanogaster $(0.156)$ was almost the same as that of $D$. simulans (0.154). These results were in accord with those of O'Brien and MacIntyre (1969), Berger (1970), Triantaphillidis et al. (1980) and Ohnishi et al. (1982). The Est-C locus was the most variable and responsible for the magnitude of average heterozygosity. At this locus, about $70-80 \%$ of individuals are hetrozygous and the contribution of this locus to total average heterozygosity nearly corresponds to the total of the other loci. Authors who did not study the Est-C locus (Steiner et al. 1976, and Ohnishi et al. 1982) reported lower average heterozygosity in $D$. simulans (Table 6). 
Table 6. Enzyme variation in several populations of Drosophila simulans

\begin{tabular}{|c|c|c|c|c|c|}
\hline & Country & $\begin{array}{l}\text { No. of } \\
\text { loci }\end{array}$ & $\begin{array}{l}\text { No. of } \\
\text { alleles per } \\
\text { locus }\end{array}$ & $\begin{array}{l}\text { Proportion of } \\
\text { polymorphic } \\
\text { loci }\end{array}$ & $\begin{array}{l}\text { Hetero- } \\
\text { zygosity }\end{array}$ \\
\hline \multirow[t]{2}{*}{$\begin{array}{l}\text { O'Brien and MacIntyre } \\
(1969)^{*}\end{array}$} & USA (Columbia) & 10 & 1.20 & 0.20 & 0.07 \\
\hline & USA (Manning) & 10 & 1.00 & 0 & 0 \\
\hline Berger (1970) & USA & 6 & 1.00 & 0 & 0 \\
\hline Kojima et al. $(1970)^{* *}$ & USA (Texas) & 18 & 2.17 & 0.556 & 0.162 \\
\hline \multirow[t]{2}{*}{ Steiner et al. (1976) } & USA (Hawaii) & 15 & 1.60 & 0.40 & 0.073 \\
\hline & USA (Oahu) & 15 & 1.33 & 0.333 & 0.073 \\
\hline$\underset{(1980)^{* *}}{\text { Triantaphyllidis et al. }}$ & Greece (Gorfu Is.) & 11 & 2.09 & 0.455 & 0.174 \\
\hline$\underset{(1982)^{* *}}{\text { Triantaphyllidis et al. }}$ & Greece & 6 & 2.13 & 0.50 & 0.172 \\
\hline \multirow[t]{2}{*}{ Ohnishi et al. (1982) } & Japan (Mishima) & 24 & - & 0.29 & 0.067 \\
\hline & USA (mixed) & 24 & - & 0.375 & 0.059 \\
\hline Present study** & Japan & 10 & 1.64 & 0.32 & 0.154 \\
\hline
\end{tabular}

*: Small number of isofemale lines studied

**: Studies including Est-C

The genetic distances were very small between years in both $D$. melanogaster and $D$. simulans. However, alleles frequencies of some loci changed significantly between years. The largest change in allele frequency between years was observed at the Est-C locus of $D$. simulans in the Shukugawa population. The collection of that population in 1977 was the first record of its distribution in the district, and the number of flies sampled was small. This may be the cause of the unusual frequency in the 1977 sample. In the Omiya population of $D$. melanogaster, allele frequencies of $A d h$ and $G 6 p d h$ changed considerably between years, although the effective population size was estimated to be about 3,300. This value was in accord with those of Japanese D. melanogaster populations estimated earlier (Kosuda et al. 1969, Yamaguchi et al. 1980). The changes in alleles frequencies between years may not have been caused by genetic drift, but may either be an experimental artifact caused by small sample size or mass migration.

\section{Genetic differentiation and geographical distribution of D. simulans}

D. simulans has successfully colonized the main islands of Japan in recent years and it is still spreading its distribution (Watanabe and Kawanishi 1976, 1978). In the course of this study, D. simulans was collected for the first time from some localities (Sapporo, Shukugawa and Okayama).

Very little genetic differentiation at the enzyme loci was revealed among the main island populations of $D$. simulans. Even between the most distant 
populations (Sapporo vs. Kagoshima), the genetic distance was estimated as 0.0020 , which is comparable to that between years at same locality (Table 5). This result suggests that populations of $D$. simulans in the Japanese main islands are probably from an ancestral population, although Ohnishi and Kawanishi (1981) suggested two different origins, at least. In the neighborhood of Japanese islands, $D$. simulans had been reported only in Ogasawara Islands before its invasion of the main islands of Japan. However, the possibility that the $D$. simulans now distributed all over the Japanese main islands derived from the Ogasawara Islands seems to be ruled out from the following fact clarified in the present study: rare alleles, such as Est- $6^{c}, A c p h^{b}$ and $O d h^{b}$, which were detected in the main island populations, had never been found in the Ogasawara population.

Table 7 shows allele frequencies of three polymorphic loci of $D$. simulans in various regions reported by previous authors. Number of major alleles at each locus and allele frequencies did not differ much among the regions. At both the Est- 6 and Acph loci similar allele frequencies were obtained all over. The low level of geographic differentiation at enzyme loci may be explained by species specific stable property or an essentially panmictic condition of $D$. simulans with great dispersal: it makes impossible to find the ancestor of the Japanese main island populations based on the allozyme data.

\section{Genetic differentiation and geographic distribution of D. melanogaster}

The present study shows some geographical differentiation of isozyme polymorphisms at several loci of $D$. melanogaster. Remarkable differentiation was found at $A d h$ locus: $A d h^{b}\left(A d h^{s}\right)$ frequency varied from 0.016 to 0.914 . It has high frequencies in the southern islands, Ogasawara and Ryukyu Islands, and decreased frequencies in the main islands where the gradual decrease in $A d h^{b}$ frequency from north to south was found, especialy in the vineyard populations. In the populations near human habitations in main islands (Hokkaido, Honshu, Shikoku, and Kyushu) $A d h^{b}$ frequency was regularly lower than those of vineyards in corresponding latitudes. This indicates that gene flow is not so great as to lose the diversity of $A d h$ allele frequency, or that an environmental gradient is more responsible for the maintenance of the cline than gene flow.

The latitudinal $A d h$ clines, decreasing $A d h^{s}$ frequency with increasing latitude, were reported in United States (Johnson and Shaffer 1973, Voelker et al. 1978), in Europe and Africa (David 1982), in Australia (Oakesshott et al. 1982), and in Japan (Watanabe and Watanabe 1977, Yamaguchi et al. 1980). Following Watanabe and Watanabe (1977) and Yamaguchi et al. (1980), if we concern all populations including Ogasawara and Ryukyu where $A d h^{S}$ is in particuraly high frequency, the similar general latitudinal cline at $A d h$ locus 
Allozyme variation in Drosophila

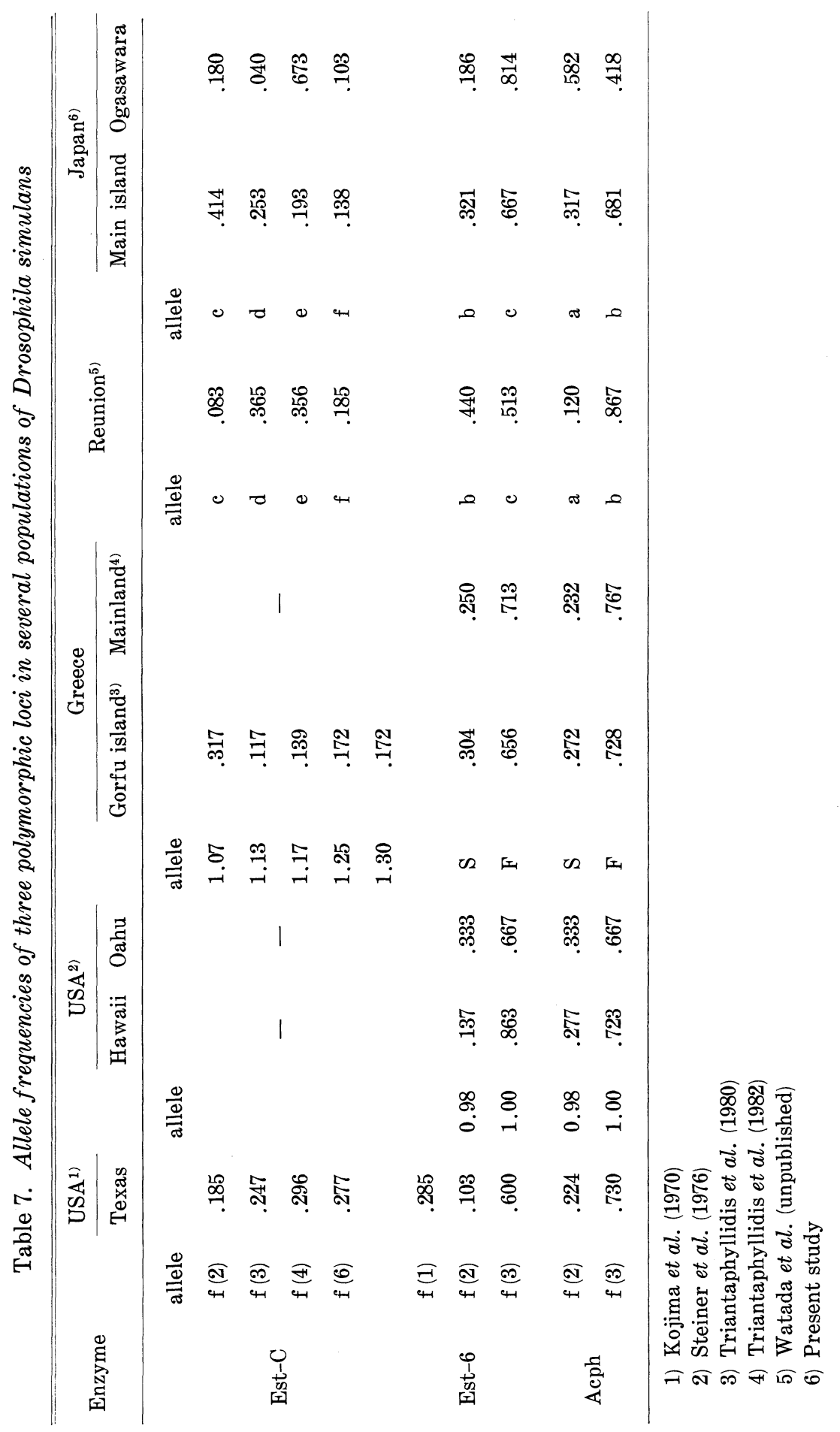


M. WATAdA, Y. N. TOBARI and S. OHBA

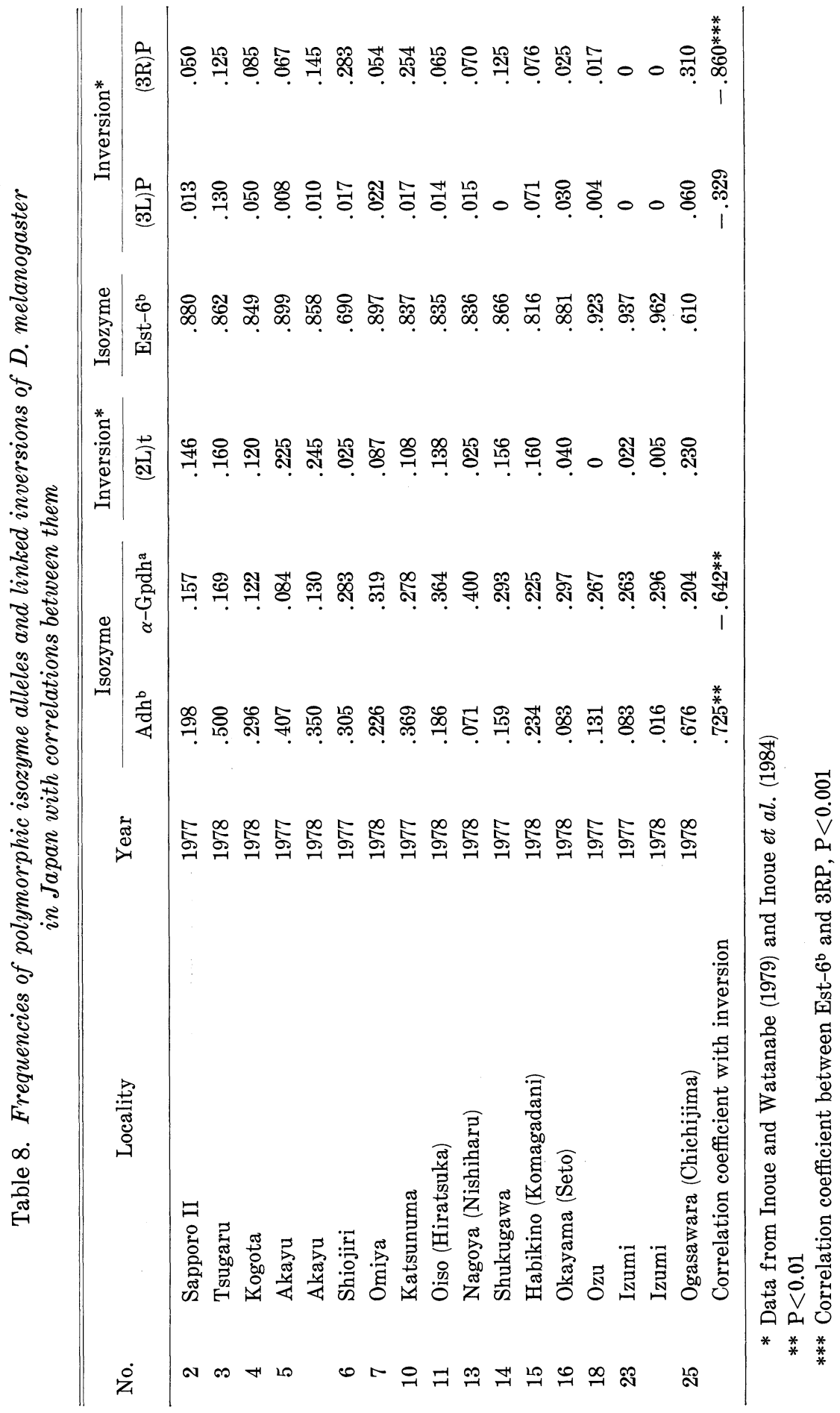


was found. However, once attention is focused on Japanese main island populations (Hokkaido, Honshu, Shikoku and Kyushu) the opposit clinal pattern, increasing $A d h^{s}$ with latitude, was found, especially in the vineyard populations. Although we have no data to explain this clinal variation, some factors such as microenvironmental variables, the frequency of linked inversion, $I h(2 L) t$, and migration might responsible for the cline.

D. melanogaster is usually polymorphic in salivary gland chromosomes (Carson 1965, Ashburner and Lumeunier 1976, Inoue 1980). Linkage disequilibria between enzyme loci and closely linked inversions have been reported in D. melanogaster (Kojima et al. 1970, Mukai et al. 1971, Langley et al. 1974). It is also evident that some inversions exhibit clinal pattern over large geographical regions. Therefore, some authors have suggested that allozyme polymorphisms would be maintained by linked polymorphic inversions which were maintained by balancing selection (Mettler et al. 1977, Watanabe and Watanabe 1977). In this study, it is possible to compare the frequencies of allozymes with those of polymorphic inversions, because 17 populations of $D$. melanogaster studied were surveyed for chromosome arrangements at the same time by Inoue and Watanabe (1979) and Inoue et al. (1984). The degree of inversion polymorphism was low in the Shikoku and Kyushu population. The positive correlation between allele frequencies and linked inversion frequencies was significant in Japanese populations of D. melanogaster (Table 8). Gene frequencies of three polymorphic loci (Adh, $\alpha$-Gpdh and Est-6) showed significant correlations with those linked inversions, although Est- 6 was not positively correlated with the closely linked inversion, $\operatorname{In}(3 L) P$, but strongly correlated with $\operatorname{In}(3 R) P$. These indicate that inversion polymorphisms are partly responsible for genetic differentiation of linked allozyme loci.

The authors wish to express our great appreciation to Dr. Y. Inoue, National Institute of Genetics, Drs. H. Ikeda and F. Hihara, Ehime University, Dr. S. C. Ishiwa, Ochanomizu University, and Dr. M. T. Kimura, Hokkaido University, for providing materials. The authors are indebted to Dr. B. L. Pierce for reading the manuscript.

\section{REFERENCES}

Ashburner, M. and Lemeunier, F. (1976) Relationship within the melanogaster species subgroup of the genus Drosophila (Sophophora) I. Inversion polymorphism in Drosophila melanogaster and Drosophila simulans. Proc. R. Soc. Lond. B. 193, 137-157.

Aotsuka, T. (1980) Genetic and reproductive differentiation during the speciation process in Drosophila bipectinata species complex. Doctors Thesis. Tokyo Metropolitan University, Tokyo.

Ayala, F. J., Powell, J. R., Tracey, M. L., Mourao, C. A. and Perez-Salas, S. (1972) Enzyme variability in the Drosophila willistoni group. IV. Genetic variation in natural populations of Drosophila willistoni. Genetics 70, 113-139.

BERGER, E. M. (1970) A comparison of gene-enzyme variation between Drosophila melanogaster and $D$. simulans. Genetics 66, 677-683.

Bock, I. R. and WheEler, M. R. (1972) The Drosophila melanogaster species group. Univ. Texas Publ. 7213, 1-102. 
Carson, H. L. (1965) Chromosomal morphism in geographically widespread species of Drosophila. In The Genetics of Colonizing Species (ed. H. G. Baker and G. L. Stebbins), pp. 503531.

DAvid, J. R. (1982) Latitudinal variability of Drosophila melanogaster: Allozyme frequencies divergence between European and Afrotropical populations. Biochem. Genet. 20, 747-761.

Dobzhansky, Th. (1965) "Wild" and "domestic" species of Drosophila. In The Genetics of Colonizing Species (ed. H. G. Baker and G. L. Stebbins), pp. 533-546.

Fukatami, A. (1977) Enzyme polymorphism in natural populations of Drosophila lutescens. Jpn. J. Genet. 52, 341-356.

HoEnigsberg, H. F. (1968) An ecological situation which produced a change in the proportion of Drosophila melanogaster and D. simulans. Amer. Natur. 102, 389-390.

Inoue, Y. (1980) Chromosomal aberration in Drosophila simulans. Ann. Rep. Natl. Inst. Genet. 30, 77-78.

InOUE, Y. and WATANABE, T. K. (1979) Inversion polymorphism in Japanese natural populations of Drosophila melanogaster. Jpn. J. Genet. 54, 69-82.

Inoue, Y., Watanabe, T. and Watanabe, T. K. (1984) Evolutionnary change of the chromosomal polymorphism in Drosophila melanogaster populations. Evolution 38, 753-765.

Johnson, F. M. and Schaffer, H. E. (1973) Isozyme variability in species of the genus Drosophila. VII. Genotype-environment relationships in populations of $D$. melanogaster from the eastern United States. Biochm. Genet. 10, 149-163.

KIKkawa, H. and Peng, F. T. (1937) Drosophila species of Japan and adjacent localities. Jpn. J. Zool. 7, 507-552.

Kojima, K., Gilliespie, J. and Tobari, Y. N. (1970) A profile of Drosophila species enzyme assayed by electrophoresis. I. Number of alleles, heterozygosities, and linkage disequilibrium in glucosemetabolizing systems and some other enzymes. Biochem. Genet. 4, 627-637.

Komai, T. (1937) Collection of D. simulans from Japan. Drosophila Inform. Serv. 8, 78.

Kosuda, K., Kitagawa, O. and MoRiwaKi, D. (1969) A seasonal survey of the genetic structure in natural populations of Drosophila melanogaster. Jpn. J. Genet. 44, 247-258.

LANGley, C. H., Tobari, Y. N. and KoJIma, K. (1974) Linkage disequilibrium in natural populations of Drosophila melanogaster. Genetics 78, 921-936.

Mettler, L. E., Voelker, R. A. and Mukai, T. (1977) Inversion cline in populations of Drosophila melanogaster. Genetics 87, 169-176.

MukAi, T. and YAMAguchi, O. (1974) The genetic structure of natural populations of Drosophila melanogaster. XI. Genetic variability in a local population. Genetics 76, 339-366.

Mukai, T., MetTler, L. E. and Chigusa, S. I. (1971) Linkage disequilibrium in a local populations of Drosophila melanogaster. Proc. Nat. Acad. Sci. USA 68, 1065-1069.

NEI, M. (1972) Genetic distance between populations. Amer. Natur. 106, 283-292.

OAkeshott, J. G., Gibson, J. B., KnibB, W. R., Anderson, D. G. and Chambers, G. K. (1982) Alcohol dehydrogenase and glycerol-3-phosphate dehydrogenase clines in Drosophila melanogaster of different continents. Evolution 36, 86-96.

O'Brien, S. J. and MAcIntyre, R. J. (1969) An analysis of gene-enzyme variability in natural populations of Drosophila melanogaster and D. simulans. Amer. Natur. 103, 97-113.

Ohnishi, S., Brown, A. J. L., Voelker, R. A. and Langley, C. H. (1982) Estimation of genetic variability in natural populations of Drosophila simulans by two-dimensional and starch gel electrophoresis. Genetics 100, 127-136.

OHnishi, S. and Kawanishi, M. (1981) The sexcomb of Drosophila simulans: Geographical variation and genetic analysis. Kontyu, Tokyo 49, 37-44.

Okada, T. (1956) Systematic study of Drosophilidae and allied families of Japan. Gihodo, Tokyo.

Steiner, W. M., Sung, K. C. and Paik, Y. K. (1976) Electrophoretic variability in island populations of Drosophila simulans and Drosophila immigrans. Biochem. Genet. 14, 495-506.

Tantawy, A. O., Maurad, A. M. and Masri, A. M. (1970) Studies on natural population of Drosophila VIII. A note on the directional changes over a long period of time in the structure of Drosophila near Alexandria, Egypt. Amer. Natur. 104, 105-109. 
Triantaphyllidis, C. D., Panourgias, J. N., Scouras, Z. G. and Ioannidis, G. C. (1980) A comparison of gene-enzyme variation between Drosophila melanogaster and Drosophila simulans. Genetica 51, 227-231.

Triantaphyllidis, C. D., Scouras, Z. G., Panourgias, J. N. and Ioannidis, G. C. (1982) Allozyme variation in Greek wild populations of Drosophila melanogaster and D. simulans along a north-south gradient. Genetica 58, 129-136.

Vigue, C. L. and Johnson, F. M. (1973) Isozyme variability in species of the genus Drosophila. VI. Frequency-property-environmental relationships of allelic alcohol dehydrogenases in $D$. melanogaster. Biochem. Genet. 9, 213-227.

Voelker, R. A., Cockerham, C. C., Johnson, F. M., Schaffer, H. M., Mukai, T. and Mettler, L. E. (1977) Inversion fails to account for allozyme clines. Genetics 88, 515-527.

Watanabe, T. K. and Kawanishi, M. (1976) Colonization of Drosophila simulans in Japan. Proc. Japan Acad. 52, 191-194.

Watanabe, T. K. and KaWANishi, M. (1978) Geographical distribution of Drosophila simulans in Japan. Zool. Mag. 87, 109-116.

Watanabe, T. K. and Watanabe, T. (1977) Enzyme and chromosome polymorphisms in Japanese natural populations of Drosophila melanogaster. Genetics 85, 319-329.

Yamaguchi, O., IChinose, M., Matsuda, M. and Mukai, T. (1980) Linkage disequilibrium in isolated populations of Drosophila melanogaster. Genetics 96, 507-522. 